\title{
Ambroxol and Ciprofloxacin Show Activity Against SARS-CoV2 in Vero E6 Cells at Clinically-
}

\section{Relevant Concentrations}

Steven B Bradfute, ${ }^{1}$ Chunyan Ye, ${ }^{1}$ Elizabeth C Clarke, ${ }^{1}$ Suresh Kumar, ${ }^{2,3}$ Graham S Timmins, ${ }^{2,4}$ and Vojo Deretic. ${ }^{2,3}$

${ }^{1}$ Center for Global Health, Department of Internal Medicine, School of Medicine, University of New Mexico Health Sciences Center, Albuquerque, NM 87131, USA

2 Autophagy, Inflammation and Metabolism (AIM) Center, School of Medicine, University of New Mexico Health Sciences Center, Albuquerque, NM 87131, USA

${ }^{3}$ Department of Microbiology and Molecular Genetics, School of Medicine, University of New Mexico Health Sciences Center, Albuquerque, NM 87131, USA

${ }^{4}$ Department of Pharmaceutical Sciences, College of Pharmacy, University of New Mexico Health Sciences Center, Albuquerque, NM 87131, USA

\section{Abstract.}

We studied the activity of a range of weakly basic and moderately lipophilic drugs against SARS CoV2 in Vero E6 cells, using Vero E6 survival, qPCR of viral genome and plaque forming assays. No clear relationship between their weakly basic and hydrophobic nature upon their activity was observed. However, the approved drugs ambroxol and ciprofloxacin showed potent activity at concentrations that are clinically relevant and within their known safety profiles, and so may provide potentially useful agents for preclinical and clinical studies in COVID-19.

\section{Introduction}

The novel severe acute respiratory syndrome coronavirus 2 like virus, (SARS-CoV2), ${ }^{1,2}$ was identified as the causative agent of the current pandemic of viral pneumonia, causing a disease termed COVID-19 (coronavirus disease-2019) by the World Health Organization, with efficient human to human transmission, and significant morbidity and mortality. The world is scrambling to develop countermeasures, including therapeutics aiming to lessen disease severity and to develop with prophylaxes including vaccines. 
Recently, FDA approved drugs, chloroquine (CQ) and hydroxychloroquine (HCQ) and azithromycin (AZT) have shown therapeutic activity against COVID-19 in initial clinical trials, ${ }^{3}$ and also in in vitro cellular systems, although subsequent clinical evidence does not suggest these are effective. All these agents are known to inhibit autophagy in humans at relevant doses, ${ }^{4-7}$ and so the field is actively looking to repurpose and develop other modulators of autophagy that may potentially show anti SARS-CoV-2 activity. Another possible mechanism we have proposed is related to their weakly basic and hydrophobic nature, whereby they may modify $\mathrm{pH}$ in acidified intracellular sites such as endosomes and the trans-Golgi network, ${ }^{8-10}$ although this has yet to be validated in the context of SARS-CoV-2 infected cells. Here, we present data upon the activity of these drugs, and also other weak bases we have studied, ciprofloxacin (CPX), ${ }^{10}$ ambroxol (AMB), and its prodrug bromhexine (BHX) against SARS-CoV2 in Vero E6 cells. Unlike the inhibition of autophagy caused by $\mathrm{CQ}, \mathrm{HCQ}, \mathrm{AZT}$ and $\mathrm{CPX}{ }^{11}$, both $\mathrm{BHX}^{12}$ and $\mathrm{AMB}^{13}$ induce execution of the complete autophagy pathway from initiation to maturation at concentrations that are clinically relevant.

\section{Materials and Methods:}

Biosafety. All procedures involving live virus were performed in a BSL3 facility with the approval of the institutional biosafety committee.

Cell death inhibition assay. Vero E6 cells were treated with the indicated compounds for 1 hour prior to infection with $0.05 \mathrm{MOI}$ of SARS-CoV-2 Isolate USA-WA1/2020 (deposited by the Centers for Disease Control and Prevention and obtained through BEI Resources, NIAID, NIH, NR52281). Forty-eight hours later, cell viability was assessed by XTT Cell Viability (ThermoFisher) using the manufacturer's protocol. Data are means +/- standard error (SE) of 3 replicates. At least one additional replicate experiment was performed for each compound.

Quantitative PCR assay. Supernatants from cells infected as above were harvested and RNA was isolated using the Qiagen Viral RNA Mini kit following the manufacturer's protocol. Primers and probes as designed by the Centers for Disease Control and Prevention were obtained from Integrated DNA Technologies 2019-nCoV RUO Kit (Cat \# 10006713). qPCR was performed using the TaqMan $^{\text {TM }}$ Fast Virus 1 -Step Master Mix (Applied Biosystems). Assays were conducted on a QuantStudio5 Q-PCR machine (Applied Biosystems), and reported as cycle threshold values (Ct). Data are means +/- standard error (SE) of 3 replicates. At least one additional replicate experiment was performed for each compound (except CPX/AMB mixtures), and representative data shown. 
Plaque Forming Unit Assay. Supernatants from infected cells as above were added to fresh Vero E6 cells and incubated for 2 hours at $37^{\circ} \mathrm{C}$ and aspirated. Cells were overlaid with $1 \mathrm{~mL}$ of a mix of $2 \%$ agarose and $2 \mathrm{X}$ minimal essential medium with $2.5 \% \mathrm{FCS}$ and incubated at $37^{\circ} \mathrm{C}$ for 2 days, followed by fixation with $4 \%$ formaldehyde. After overlay removal, cells were stained with $0.5 \%$ crystal violet, washed, and dried. Plaques were counted for determination of viral titer.

Statistical Analysis. Analyses were performed with GraphPad (GraphPad Prism 7.0) and Sigma Stat (Sigma Stat 3.0).

\section{Results}

The first assay used was based upon survival of Vero E6 cells after infection with SARS-CoV2, so that antiviral effects will manifest themselves as increases in cell survival, commonly referred as protection against cytopathic effect. For the autophagy-inhibiting weak base agents, robust and dosedependent increases in survival were observed for both $C Q$ and CPX, while AZT had no effect (Figure 1). For the autophagy inducing weak bases a dose dependent increase in survival was observed for AMB but not for BHX (Figs. 1 and 2). The second assay used was quantitative PCR (qPCR) of SARS-CoV2 genome to determine the effect of replication, so that antiviral effects will manifest themselves as increases in cycle threshold value (Ct). For the autophagy inhibiting weak bases, AZT at $10 \mu \mathrm{M}$ had no effect on $\mathrm{Ct}, 10 \mu \mathrm{M} \mathrm{CQ}$ showed a moderate increase in $\mathrm{Ct}$, while CPX caused a marked and dose-dependent increase in Ct (Fig 3). For the autophagy inducing weak bases, AMB showed a dose-dependent increase in $\mathrm{Ct}$, with highest activity at $100 \mu \mathrm{M}$. (Fig. 3). When AMB (10 or $100 \mu \mathrm{M})$ and CPX $(10 \mu \mathrm{M})$ were combined, the effects appeared antagonistic. Finally, the third assay used was a plaque formation assay to confirm that the qPCR results are indicative of true infective viral units (Fig 4). CPX showed a marked and dose dependent decrease in viral titer (Fig. 4), the highest concentrations of AMB and CQ showed modest reductions, and AZT showed no effect.

\section{Discussion}

Our initial hypothesis was based around the neutralization of organelle acidification, ${ }^{8-10}$ enabled by the weakly basic and lipophilic properties of the compounds used (Table 1). Despite broad similarities in their physical-chemical properties, there was no broad effect of all compounds on Vero E6 survival or viral replication, with AMB, CPX and CQ showing activity while AZT and BHX did not. Nor was there any clear correlation of activity depending upon autophagy status: of the inhibitors, 
CPX and CQ showed activity, while the inducer AMB also showed effects. Therefore, while their weakly basic and lipophilic nature may enable all these drugs to access and neutralize acidified organelles, this does not explain the anti-SARS-CoV2 activity of some of these, nor the absence of activity of others, in Vero E6 cells. Thus, additional mechanisms of action, including those that are directly anti-viral or affecting entry or other aspects of SARS-CoV-2 replication, transcription, and propagation, are postulated here.

The activities of AMB and CPX were achieved at concentrations that are relevant to the lung tissue levels reached at known safe therapeutic doses. AMB is highly safe in both adult and pediatric use. $^{14,15}$ It has also been shown safe in long term use at high doses in Parkinson's disease (1260mg $\mathrm{q} 24 \mathrm{~h})^{16}$ and Gaucher disease $(27 \mathrm{mg} / \mathrm{kg} \mathrm{q} 24 \mathrm{~h})^{17}$ and doses of this magnitude are known to lead to lung levels approaching $100 \mu \mathrm{M}$, the most effective concentration in this work, because of the potent lung tropism of this compound in humans. ${ }^{18}$ Furthermore, high dose AMB (15-20 mg/kg/day) has been shown both safe and also to reduce inflammatory cytokines in acute respiratory distress syndrome (ARDS), ${ }^{19}$ and so potential trials in COVID-19 of high dose AMB may be warranted.

Mean CPX lung levels after a $500 \mathrm{mg}$ dose were have been observed as being above the most effective concentration here, $10 \mu \mathrm{M}$, for up to 4 hours after dosage, ${ }^{20}$ again demonstrating that the concentrations used here are clinically relevant. However, although a more potent agent in our hands than AMB, CPX has black box warnings for several adverse events. However, if its' clinical activity is as superior as shown here in cells, its risk/benefit ratio may still be favorable, as both risk and benefit are higher. Retrospective analysis in COVID-19 cases treated with CPX (in secondary lung infection for example) should be conducted for determination of potential benefit. Since an inhaled form of CPX has been developed (Linhaliq reached Phase 3), this may lower systemic exposure while maintaining efficacy. The effects of combined AMB and CPZ on viral replication appear antagonistic, although additional studies are required.

AMB appears to have a separate and distinct activity from the TMPRSS2-dependent activity of $\mathrm{BHX}$, and so the combination of these two drugs (high dose $\mathrm{AMB}$ and regular dose $\mathrm{BHX}$ ), although counter-intuitive as $B H X$ is the prodrug of $A M B$, may prove useful. This is especially so, as $A M B$ is known to be safe at much higher doses than BHX, with these high doses also showing effects in ARDS that would be highly desirable in COVID-19 patients; increasing oxygenation $\left(\mathrm{PaO}_{2} / \mathrm{FiO}_{2}\right.$ ratio, $\mathrm{PO}_{2}$ and $\mathrm{SaO}_{2}$ ) while also reducing inflammatory markers (TNF- $\alpha$ and IL-6). ${ }^{19}$ 
Mechanistically, $\mathrm{BHX}$ is a potent inhibitor of the protease TMPRSS2, ${ }^{21}$ whose activity is necessary for SARS-CoV2 entry into many cell types, ${ }^{22}$ including respiratory epithelia, and so its lack of effects here might be considered puzzling. However, recent work shows that Vero E6 cells do not express TMPRSS2, and instead viral entry is achieved through an alternative and CQ-inhibited pathway . ${ }^{23}$ Thus, BHX may show benefits in cells where SARS-CoV-2 entry depends on TMPRSS2. However, in our hands, AMB appears to have a separate and distinct antiviral activity from that of $\mathrm{BHX}$, with $\mathrm{BHX}$ being hypothesized ${ }^{24}$ and trialed ${ }^{25}$ as a repurposed treatment for COVID-19. Although the mechanisms of action of AMB and CPX against SARS-CoV2 in Vero E6 cells remain to be elucidated, there are some possibilities. In our previous studies, AMB was more potent than BHX in inducing autophagy ${ }^{12,13}$ and so it is possible that this reflects its higher activity here, or other target(s) may be important. Fluoroquinolones such as CPX act against susceptible bacteria by preferentially binding to single strand microbial nucleic acid, ${ }^{26}$ and this then forming an inhibitory ternary complex with either DNA gyrase or topoisomerase; the activity of CPX observed here may result from a similar inhibitory ternary complex with viral RNA and viral proteins such as helicase or RNA polymerase.

Acknowledgements VD was supported by NIH grants R37AI042999 and R01Al111935 and center grant P20GM121176.

Study Strengths. The activities of AMB and CPX were confirmed in three independent assays and were achieved at clinically-relevant concentrations.

Study Weaknesses. Only one cell line, Vero E6, was used. Vero E6 cells do not express TMPRSS2, a potential target of $\mathrm{BHX}$. 


\section{Figure Legends}

Figure 1. The effect of compounds on Vero E6 cell survival 48 hours after treatment with SARS CoV2. Control cells were uninfected, and represented $100 \%$ survival. Data are means of $n=3+/-\mathrm{SE}$ from a representative of two separate experiments. Cells were treated with compounds at the micromolar concentrations shown. * Denotes significantly different $(p<0.05)$ from no drug sample by ANOVA.

Figure 2. The effect of ambroxol (AMB) and bromhexine (BHX) on Vero E6 cell survival 48 hours after treatment with SARS CoV2. Control cells were uninfected, and represented $100 \%$ survival. Data are means of $n=3+/$ - SE from a representative of two separate experiments. Cells were treated with compounds at the micromolar concentrations shown. * Denotes significantly different $(p<0.05)$ from no drug sample by ANOVA.

Figure 3. The effect of compounds on the cycle thresholds (Ct) for qPCR of viral RNA in supernatents from Vero E6 after treatment with SARS CoV2. Control cells were uninfected, and represented $100 \%$ survival. Data are means of $n=3+/$ - SE from a representative of two separate experiments (AMB/CPX combination was from a single experiment). Cells were treated with compounds at the micromolar concentrations shown. * Denotes significantly different $(p<0.05)$ from no drug sample by ANOVA.

Figure 4. The effect of compounds on plaque forming units per milliliter (pfu/ml) in supernatants from Vero E6 after 48 treatment with SARS CoV2. Data are shown as average (solid diamond) and range (triangle), $\mathrm{n}=2$ from a single experiment. Cells were treated with compounds at the micromolar concentrations shown. The data for $10 \mu \mathrm{M} \mathrm{CPX}$ were below the level of detection in this assay, $10^{5}$ $\mathrm{pfu} / \mathrm{ml}$. 


\section{References}

$\mathrm{Wu}, \mathrm{F}$. et al. A new coronavirus associated with human respiratory disease in China. Nature 579, 265-269, doi:10.1038/s41586-020-2008-3 (2020). Zhou, P. et al. A pneumonia outbreak associated with a new coronavirus of probable bat origin. Nature 579, 270-273, doi:10.1038/s41586-020-2012-7 (2020). Gautret, P. et al. Hydroxychloroquine and azithromycin as a treatment of COVID-19: results of an open-label non-randomized clinical trial. Int J Antimicrob Agents, 105949, doi:10.1016/j.ijantimicag.2020.105949 (2020). Mauthe, M. et al. Chloroquine inhibits autophagic flux by decreasing autophagosomeIysosome fusion. Autophagy 14, 1435-1455, doi:10.1080/15548627.2018.1474314 (2018). Renna, M. et al. Azithromycin blocks autophagy and may predispose cystic fibrosis patients to mycobacterial infection. J Clin Invest 121, 3554-3563, doi:10.1172/JCI46095 (2011). Loaiza-Bonilla, A. et al. Phase II trial of autophagy inhibition using hydroxychloroquine (HCQ) with FOLFOX/bevacizumab in the first-line treatment of advanced colorectal cancer. $J$ Clin Oncol 33, doi:DOI 10.1200/jco.2015.33.15_suppl.3614 (2015). Xu, R., Ji, Z. Y., Xu, C. \& Zhu, J. The clinical value of using chloroquine or hydroxychloroquine as autophagy inhibitors in the treatment of cancers A systematic review and meta-analysis. Medicine 97, doi:ARTN e12912 10.1097/MD.0000000000012912 (2018). Perkett, E. A., Ornatowski, W., Poschet, J. F. \& Deretic, V. Chloroquine normalizes aberrant transforming growth factor beta activity in cystic fibrosis bronchial epithelial cells. Pediatr Pulmonol 41, 771-778, doi:10.1002/ppul.20452 (2006).

9 JF, P., EA, P., GS, T. \& V, D. Azithromycin and ciprofloxacin have a chloroquine-like effect on respiratory epithelial cells. BioRxiv, doi:https://doi.org/10.1101/2020.03.29.008631 (2020). Poschet, J. F., Perkett, E. A., Timmins, G. S. \& Deretic, V. Azithromycin and ciprofloxacin have a chloroquine-like effect on respiratory epithelial cells. bioRxiv, doi:10.1101/2020.03.29.008631 (2020).

11 Fukumoto, R. et al. Ciprofloxacin modulates cytokine/chemokine profile in serum, improves bone marrow repopulation, and limits apoptosis and autophagy in ileum after whole body ionizing irradiation combined with skin-wound trauma. PloS one 8, e58389, doi:10.1371/journal.pone.0058389 (2013).

12 Chauhan, S. et al. Pharmaceutical screen identifies novel target processes for activation of autophagy with a broad translational potential. Nature communications 6, doi:ARTN 8620 10.1038/ncomms9620 (2015).

13 Choi, S. W. et al. Ambroxol Induces Autophagy and Potentiates Rifampin Antimycobacterial Activity. Antimicrobial agents and chemotherapy 62, doi:10.1128/AAC.01019-18 (2018).

14 Cazan, D., Klimek, L., Sperl, A., Plomer, M. \& Kolsch, S. Safety of ambroxol in the treatment of airway diseases in adult patients. Expert Opin Drug Saf 17, 1211-1224, doi:10.1080/14740338.2018.1533954 (2018).

15 Kantar, A. et al. An overview of efficacy and safety of ambroxol for the treatment of acute and chronic respiratory diseases with a special regard to children Multidisciplinary Respiratory Medicine 15, doi: https://doi.org/10.4081/mrm.2020.511 (2020).

16 Mullin, S. et al. Ambroxol for the Treatment of Patients With Parkinson Disease With and Without Glucocerebrosidase Gene Mutations: A Nonrandomized, Noncontrolled Trial. JAMA Neurol, doi:10.1001/jamaneurol.2019.4611 (2020).

17 Kim, Y. M. et al. Pharmacologic properties of high-dose ambroxol in four patients with Gaucher disease and myoclonic epilepsy. J Med Genet, doi:10.1136/jmedgenet-2019-106132 (2019). Mezzetti, M. et al. A pharmacokinetic study of pulmonary tropism of ambroxol in patients under thoracic surgery. The Journal of Emergency Surgery and Intensive Care 13, 179-185 (1990). 
19 Wu, X. D. et al. Meta-analysis of High Doses of Ambroxol Treatment for Acute Lung Injury/Acute Respiratory Distress Syndrome Based on Randomized Controlled Trials. J Clin Pharmacol 54, 1199-1206, doi:10.1002/jcph.389 (2014).

20 Rohwedder, R. et al. Penetration of ciprofloxacin and metabolites into human lung, bronchial and pleural tissue after 250 and 500 mg oral ciprofloxacin. Chemotherapy 37, 229-238, doi:10.1159/000238860 (1991).

21 Lucas, J. M. et al. The androgen-regulated protease TMPRSS2 activates a proteolytic cascade involving components of the tumor microenvironment and promotes prostate cancer metastasis. Cancer Discov 4, 1310-1325, doi:10.1158/2159-8290.CD-13-1010 (2014).

22 Hoffmann, M. et al. SARS-CoV-2 Cell Entry Depends on ACE2 and TMPRSS2 and Is Blocked by a Clinically Proven Protease Inhibitor. Cell 181, 271-280 e278, doi:10.1016/j.cell.2020.02.052 (2020).

23 Hoffmann, M. et al. Chloroquine does not inhibit infection of human lung cells with SARS-CoV2. Nature, doi:10.1038/s41586-020-2575-3 (2020).

24 Stopsack, K. H., Mucci, L. A., Antonarakis, E. S., Nelson, P. S. \& Kantoff, P. W. TMPRSS2 and COVID-19: Serendipity or Opportunity for Intervention? Cancer Discov 10, 779-782, doi:10.1158/2159-8290.CD-20-0451 (2020).

25 Ansarin, K. et al. Effect of bromhexine on clinical outcomes and mortality in COVID-19 patients: A randomized clinical trial. Biolmpacts 10, 209-215, doi:10.34172/bi.2020.27 (2020). Shen, L. L. \& Pernet, A. G. Mechanism of inhibition of DNA gyrase by analogues of nalidixic acid: the target of the drugs is DNA. Proceedings of the National Academy of Sciences of the United States of America 82, 307-311, doi:10.1073/pnas.82.2.307 (1985). 
bioRxiv preprint doi: https://doi.org/10.1101/2020.08.11.245100; this version posted August 11,2020 . The copyright holder for this preprint (which was not certified by peer review) is the author/funder, who has granted bioRxiv a license to display the preprint in perpetuity. It is made available under aCC-BY-NC-ND 4.0 International license.

\begin{tabular}{|l|c|c|l|c|c|}
\hline Drug & IogP & Amine pKa & $\begin{array}{c}\text { Autophagic } \\
\text { effect }\end{array}$ & $\begin{array}{c}\text { Effect on Vero E6 } \\
\text { Survival }\end{array}$ & $\begin{array}{c}\text { Effect of SARS-CoV2 } \\
\text { replication }\end{array}$ \\
\hline AZT & 4.0 & $8.2,8.6$ & Inhibits & - & - \\
\hline CPX & 1.3 & 8.7 & Inhibits & +++ & +++ \\
\hline CQ & 4.6 & 10.1 & Inhibits & +++ & ++ \\
\hline AMB & 2.6 & 9.0 & Induces & ++ & ++ \\
\hline BHX & 4.3 & 9.3 & Induces & - & n.d. \\
\hline
\end{tabular}

Table 1. Selected properties of weak base drugs used. Not performed, n.d. 

available under aCC-BY-NC-ND 4.0 International license.

\section{Figure 1.}

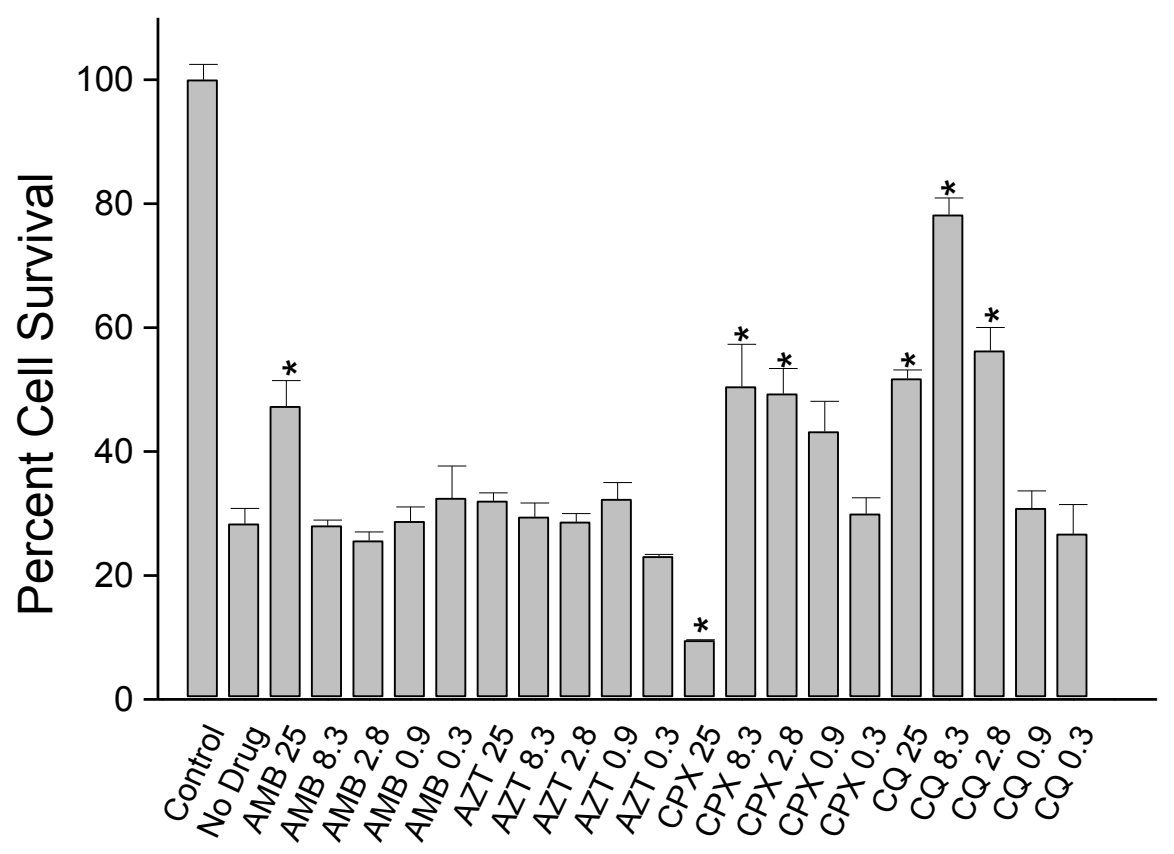


bioRxiv preprint doi: https://doi.org/10.1101/2020.08.11.245100; this version posted August 11, 2020. The copyright holder for this preprint (which was not certified by peer review) is the author/funder, who has granted bioRxiv a license to display the preprint in perpetuity. It is made available under aCC-BY-NC-ND 4.0 International license.

Figure 2.

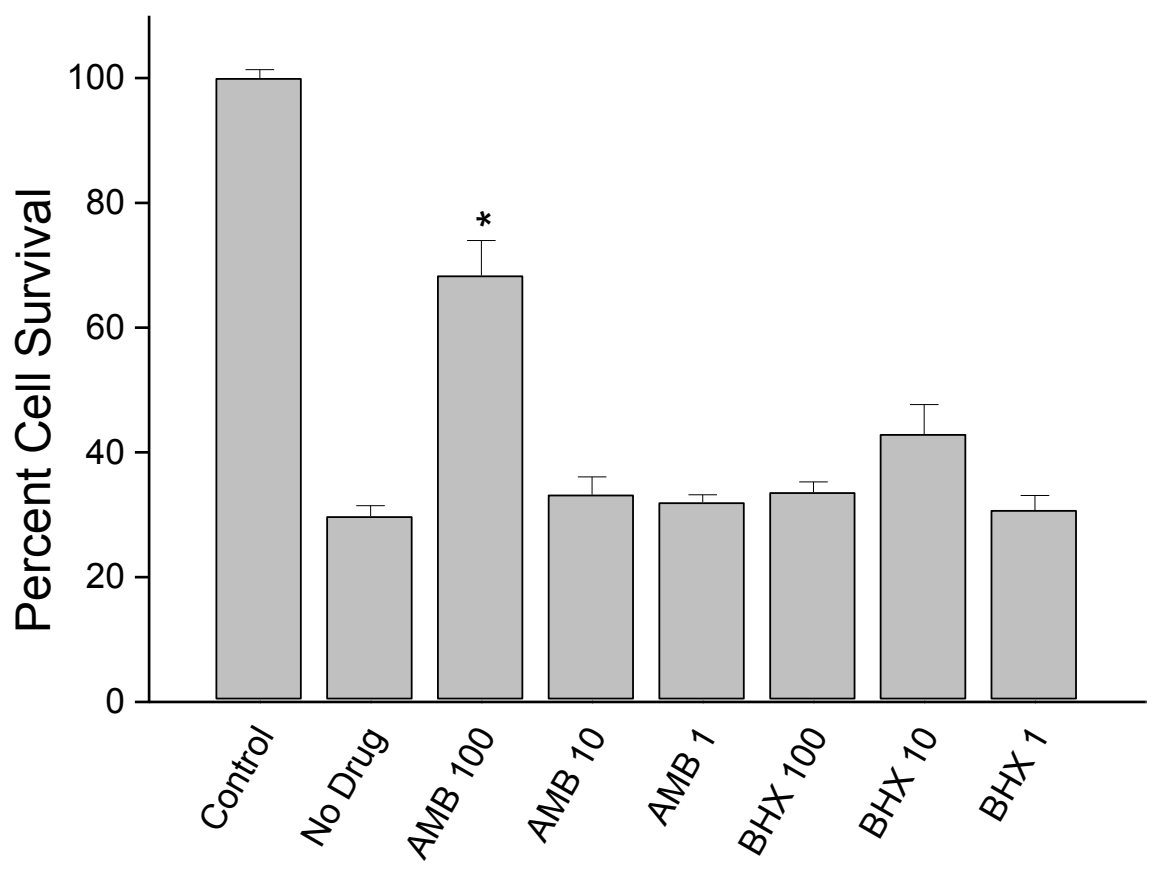


bioRxiv preprint doi: https://doi.org/10.1101/2020.08.11.245100; this version posted August 11, 2020. The copyright holder for this preprint (which was not certified by peer review) is the author/funder, who has granted bioRxiv a license to display the preprint in perpetuity. It is made available under aCC-BY-NC-ND 4.0 International license.

Figure 3

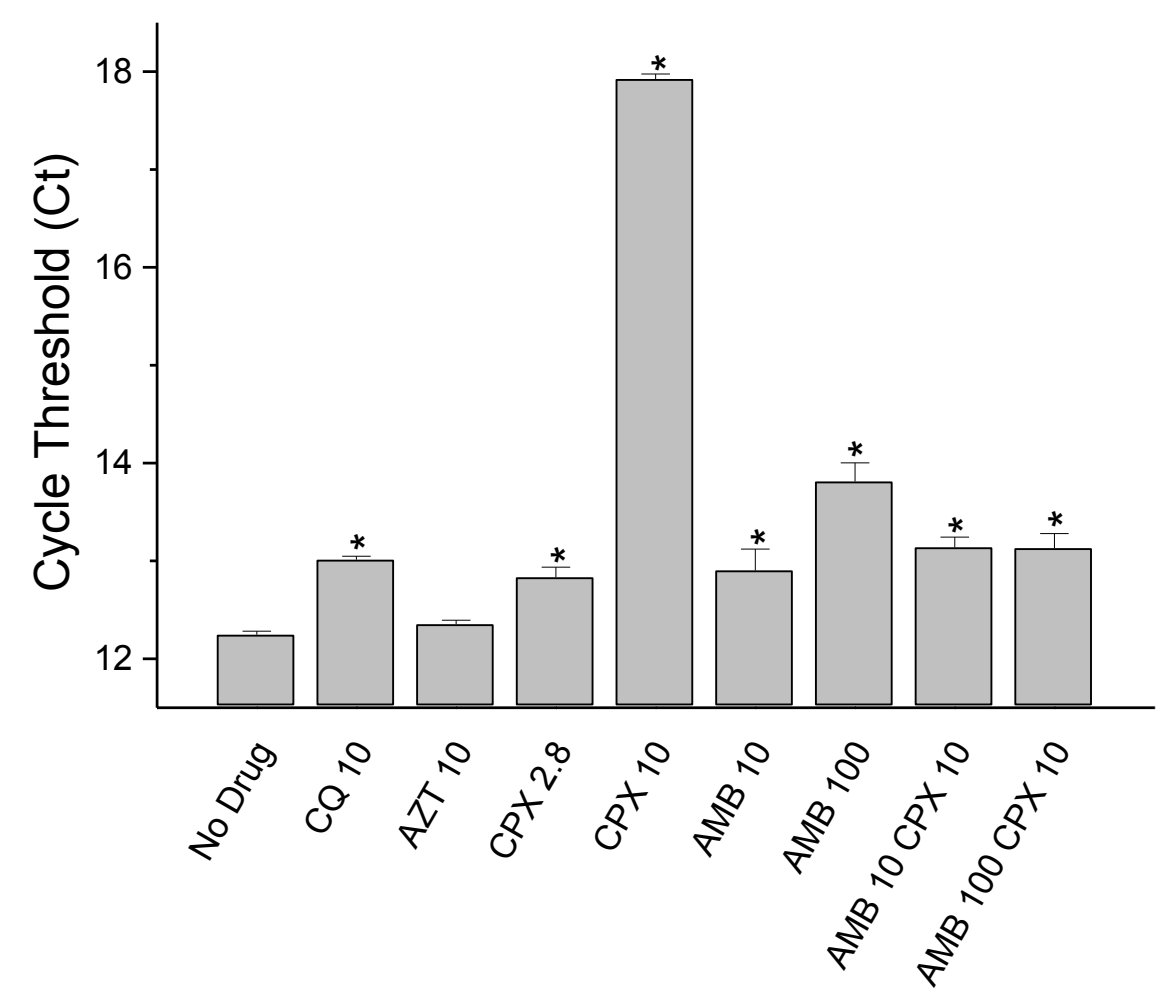


bioRxiv preprint doi: https://doi.org/10.1101/2020.08.11.245100; this version posted August 11,2020 . The copyright holder for this preprint (which was not certified by peer review) is the author/funder, who has granted bioRxiv a license to display the preprint in perpetuity. It is made available under aCC-BY-NC-ND 4.0 International license.

\section{Figure 4}

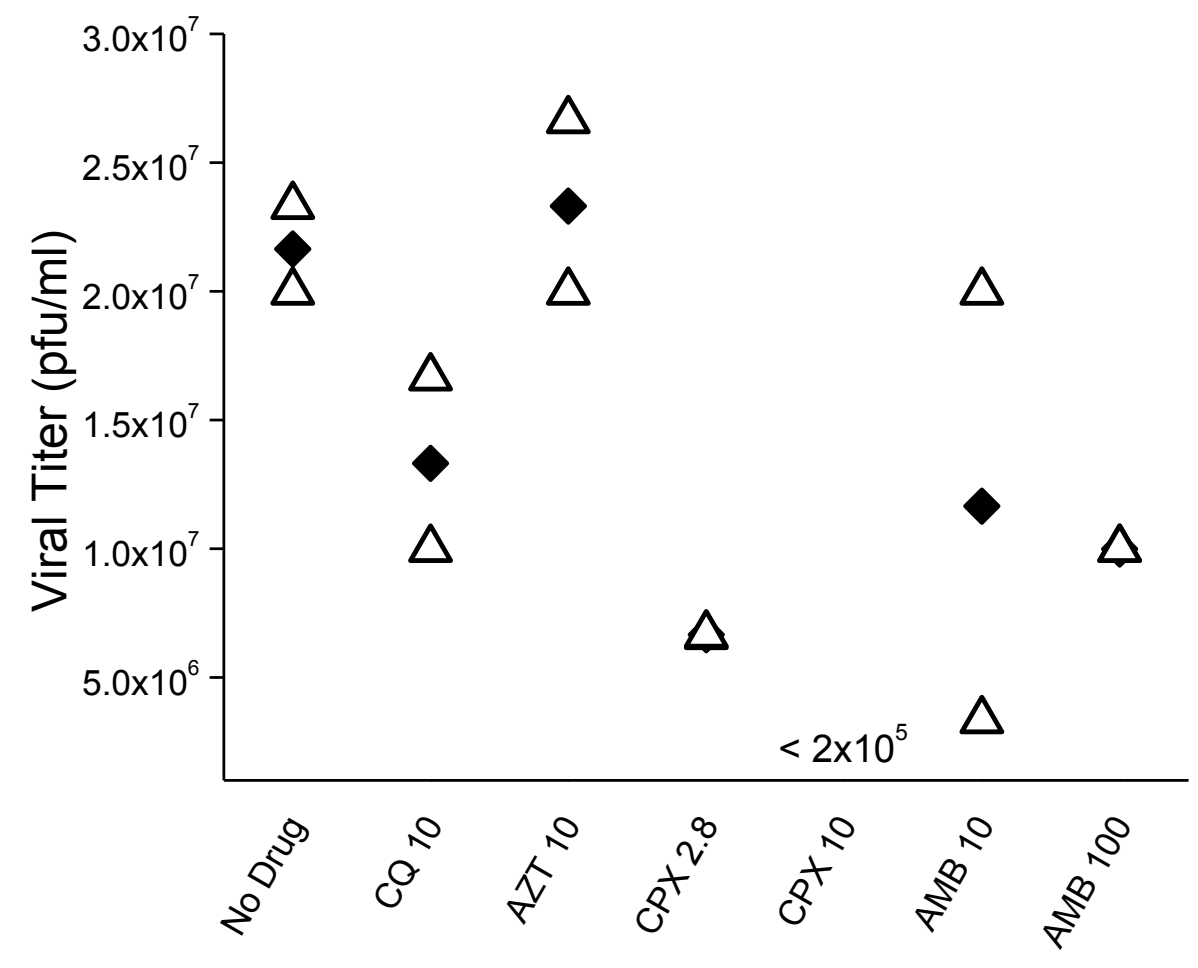

